Article

\title{
Ground Loss and Static Soil-Structure Interaction during Urban Tunnel Excavation: Evidence from the Excavation of the Athens Metro
}

\author{
Villy Kontogianni ${ }^{1, *}$ and Stathis C. Stiros ${ }^{2}$ D \\ 1 Hellenic Survey for Geology and Mineral Exploration (HSGME—former IGME), Sp. Loui 1, Olympic Village, \\ 13677 Acharnes, Greece \\ 2 Department of Civil Engineering, Patras University, 26500 Patras, Greece; stiros@upatras.gr \\ * Correspondence: villy@igme.gr
}

Received: 23 June 2020; Accepted: 28 July 2020; Published: 31 July 2020

check for updates

\begin{abstract}
Ground settlement above urban tunnels is a threat for nearby buildings, because it may lead to their differential settlement, tilting, and damage, depending on their structural characteristics, on ground conditions, and on the excavation procedure. Still, for few cases only details on ground settlement are known. In this article we analyze ground subsidence data during the excavation of Lines 2 and 3 of the Athens Metro. Based on this evidence, and in comparison with previous studies, we show that observations of elevation changes and of tilting of buildings may underestimate the amount of ground loss; this is because part of the ground deformation may be compensated by the stiffness of buildings or accommodated by internal deformation of sizeable buildings hosting measuring benchmarks. This effect can be described as static soil-structure interaction (sSSI), in analogy to the dynamic SSI produced during earthquakes. sSSI can produce bias in monitoring data above an advancing tunnel front, leading to skew and not to symmetric subsidence curves if observations are made on one side on buildings and on the other side in open spaces ('greenfields'). Furthermore, we show that 'bowls' of increased subsidence are observed along subsidence troughs during excavation; such 'bowls', not infrequently underestimated because of sSSI, may conceal a potential for sinkholes and other types of failure. Isolated towers on the contrary describe well ground subsidence and tilting.
\end{abstract}

Keywords: ground settlement; geodetic monitoring; tunnel excavation; building damage; soil structure interaction

\section{Introduction}

Tunnels represent important civil infrastructures, tend to be excavated in increasingly adverse conditions, and their construction is not without problems. The reason is that tunnel excavation produces a rearrangement of stresses around the void produced by the excavation and deformation of its surrounding rock mass, usually reaching the ground surface and known as 'ground loss'. In terms of topography, ground loss takes the form of a subsidence trough, with maximum above the axis of a shallow (up to $30 \mathrm{~m}$ deep) tunnel and attenuating away from it, at distances usually 2-3 times the tunnel diameter [1]. Such ground deformation is obviously a threat for overlying buildings, and for this reason, since the experience gained by the excavation of the Chicago Metro by Karl Terzaghi (see [2]), a main task during tunnel excavation is to model, observe, control, and minimize surface ground subsidence, including time-dependent deformation. In fact, there are numerous examples of structural deformation and damage especially of flexible masonry buildings during excavation of nearby tunnels [3,4], even in the case of small ground movements [5]. The effects of tunneling are even more apparent at high, slender structures, such as towers, chimneys, or minarets. The most known 
example is the controlled tilting of the Big Ben Clock Tower in London during the excavation of the Jubilee Metro Line extension, passing at a distance of $30 \mathrm{~m}$ from the Clock Tower [6]. Still, modeling and prediction of ground loss proved not easy. Theoretical modeling by closed functions proved not successful, numerical models are limited by the uncertainty and variability of ground strength parameters in urban environment, while the quasi-empirical model of a Gauss-type curve proposed by Peck in 1969 [1], or its variations [7], remains the most popular method for ground loss modeling.

On the other hand, despite the large number of tunneling projects combined with geodetic measurements of ground subsidence [4,6,8-14], the available information on the ground loss is limited. This is due to two reasons: (1) in each project, the amount and distribution of monitoring points is limited, usually confined to buildings at risk (Figure 1a), mainly for cost-suppression and practical reasons (for example benchmarks on the ground above or near the tunnel axis are frequently destroyed during the project) and (2) monitoring data are rarely available because of their legal and financial implications in case of failure (cf. [15]).

Such limitations are reflected in two critical, interrelated problems.

First, measurements of ground subsidence of large buildings usually indicate moderate amounts of subsidence and tilting $[4,14,16]$, but on the contrary, measurements on benchmarks on free-field (or greenfields), on posts and fences, and on isolated towers show higher, even extreme amounts of tilting and conspicuously of ground subsidence (Figure 1b; [6]). This was clearly detected during excavation of the Athens Metro at the Gazi area indicating a complex pattern of surface ground deformation and tilting of up to $0.75 \%$ of the two $\approx 30 \mathrm{~m}$ high old brick chimneys at the site (Figure 2, [17]), in contrast, minor deformation was recorded at adjacent massive buildings. This contrast, however, is not limited to tunneling, but it tends to indicate a more general effect: for example, in Venice, widespread differential ground subsidence produces important tilting to isolated towers, but not to nearby massive buildings (Figure 1c).

Second, in several cases of tunneling, observations on buildings provided evidence of moderate ground deformation and absence of structural damage in buildings, but sinkholes have been produced in open, nearby spaces, mostly roads. Such an example is an $8 \mathrm{~m}$-wide sinkhole in Ottawa city in 2016, during the construction of the light rail tunnel through weak ground [18]. A similar sinkhole had been reported much earlier during the Athens Metro construction (Figure 3, [19]). Such effects in many cases probably indicate accumulation of ground deformation not identified by monitoring on nearby buildings [20].

Hence, studies of ground loss based on observations on bulky buildings tend to underestimate the true ground loss, because of the potential of buildings to affect their deformation, as a result of the stiffness or of the internal deformation of the structures. In analogy to soil-structure interaction (SSI) in earthquake engineering (for example [21]), this effect can be regarded as static Soil-Structure Interaction, sSSI [3,22]; a complicated, geotechnical effect, with high impacts for tunneling.

In this article we present and analyze monitoring data from different projects of the excavation of Lines 2 and 3 of Athens Metro about 15 years ago. These data, until recently confidential, can provide not only a qualitative, but also a quantitative approach to the role of sSSI and of the associated greenfield (free-field) effect in the modeling of ground loss during tunnel excavation. 

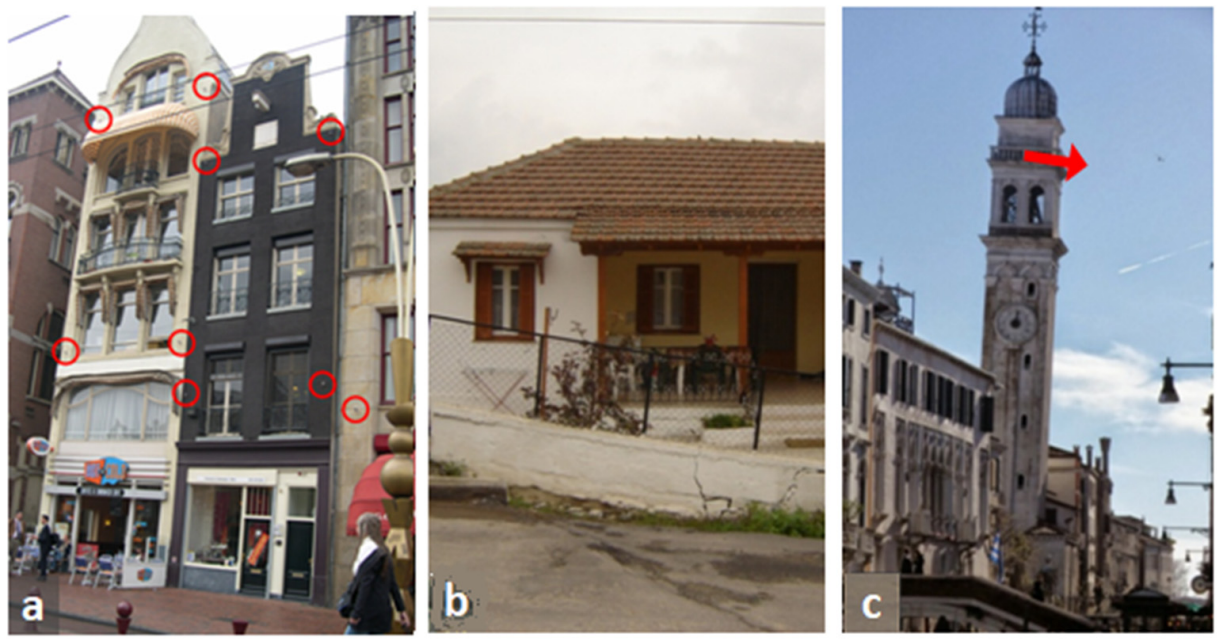

Figure 1. The static soil-structure interaction (sSSI) and the 'greenfield effect' manifested as contrast in the amplitude of tilting between whole buildings (ground loss and tilting partly concealed) and isolated towers (local tilting evident): (a) monitoring points (indicated by circles) in the facades of Amsterdam buildings for the metro excavation study. 2-D displacement only (settlement and tilting down-to-the-street) can be recorded, but not tilting parallel to the street because it is compensated by adjacent buildings. (b) Evidence of ground subsidence on the road pavement and on a stone wall (fence) at the plain of Thessaly, Greece, due to water overpumping. The rigid wall responded to ground subsidence with some hysteresis; on the contrary, the building made with stiff concrete foundations showed no significant evidence of damage (after [20]). (c) Regional ground subsidence in Venice produces limited tilting in massive buildings (palazzos and churches), but high tilting in bell towers (campanile), such as that of San Giorgio dei Greci (tilting indicated by red arrow).

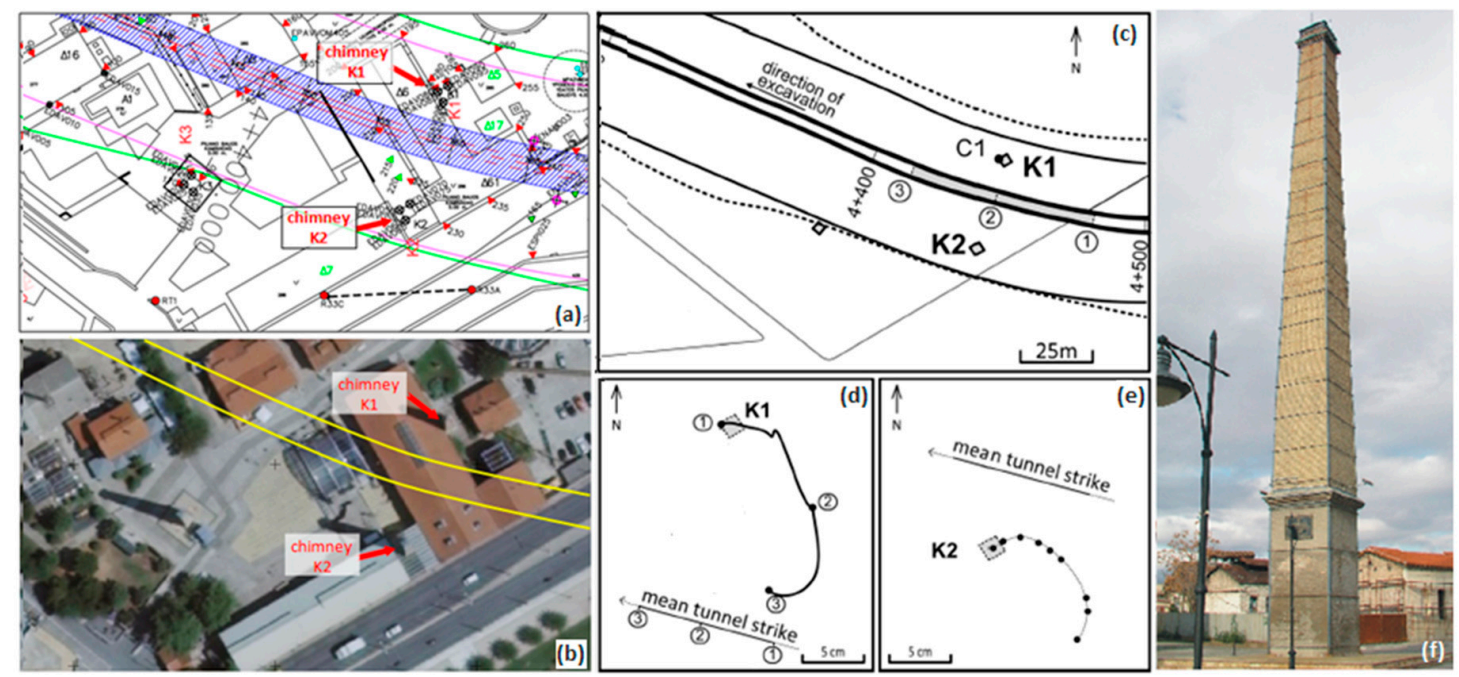

Figure 2. Contrasting evidence of ground loss during the excavation of the Athens Metro Line 3in the Gazi area from buildings and chimneys, based on geodetic monitoring. (a) Benchmarks on buildings (black and red symbols) indicate limited ground loss, but benchmarks on the $30 \mathrm{~m}$-high chimneys indicate a 3-D deformation, summarized in (d), (e) and tilting up $0.75 \%$. The tunnel path is shaded, and the predicted influence limits are shown by purple and green lines. (b) Aerial view of the Gazi area (map of the Hellenic Cadastre) of the area in (a). The excavation route is marked by two yellow curves. (c) A simplified sketch of the area around chimneys K1 and K2 showing the advancement of the tunnel front. Predicted limits of the tunnel influence zone are marked by continuous and dotted lines. (d,e) Summary of observations of movement of the center of gravity of chimneys K1, K2 near their top. (f) Side view of the K2 chimney; in the background, some of the buildings which provided evidence of minimal subsidence. Based on [17] and unpublished data. 

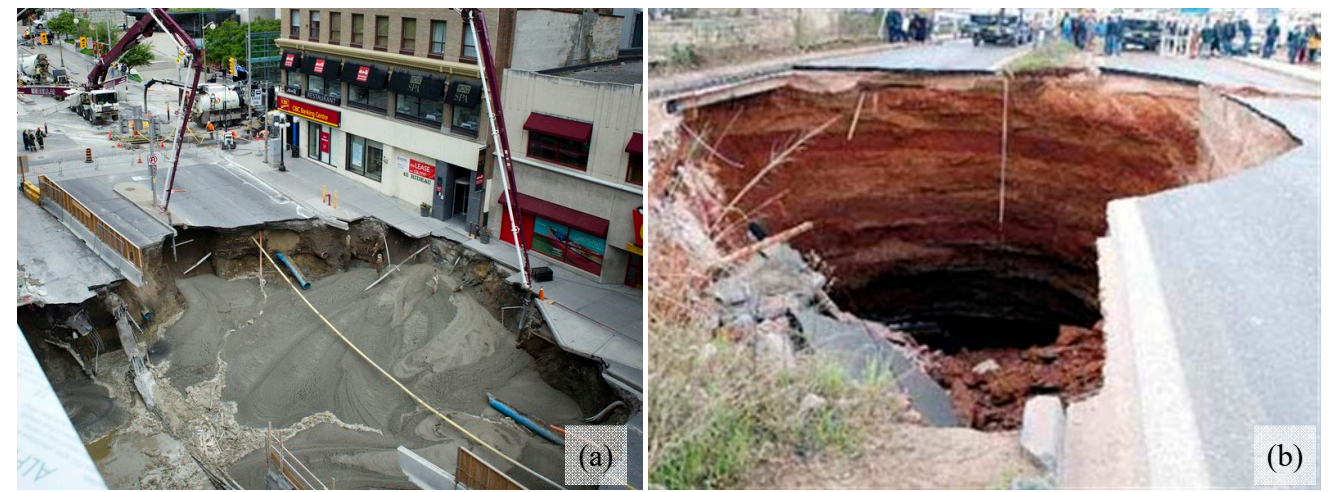

Figure 3. The problem of confidentiality in tunnel excavation data: (a) A sinkhole $8 \mathrm{~m}$ wide and $12 \mathrm{~m}$ deep opened up at the construction site of Ottawa's light rail tunnel in 2016 [18]. (b) A 10 m wide and $15 \mathrm{~m}$ deep sinkhole opened up during tunneling beneath Doukissis Plakentias Ave., Athens for the Metro Line 3 in 2003 [19]. In both cases poor ground conditions have been reported but no other technical information is available.

\section{Theoretical Modeling of Ground Loss}

The simplest and most efficient way to describe ground loss was proposed by Peck [1]. A settlement trough is predicted on the ground surface along the tunnel axis. The 2-D deformation of the ground surface $S_{v}(x)$ in a section normal to the tunnel axis is described by Equation (1):

$$
S_{v}(x)=S_{v \max } \cdot \exp \left(-\frac{x^{2}}{2 \cdot i^{2}}\right)
$$

whereas $S_{v \max }$ is the maximum settlement above the tunnel axis, $x$ is the horizontal distance from the tunnel axis, and $i$ is a parameter defining the shape of the subsidence curve in analogy to the standard deviation of the normal distribution. Parameters $S_{v \max }$ and $i$ are unknown and can be computed from inversion of observations of ground subsidence. A characteristic of this curve, shown in Figure 3a, is its symmetry, a point to be discussed in a later section, and describes nearly ideal conditions, with a uniform distribution of observations for a tunnel excavated at nearly uniform geotechnical conditions. Experience from various tunnels indicates that Equation (1) describes ground loss well. A characteristic example is shown in Figure 3b, from the Budapest metro, a traditional and representative example of tunneling [23]. Leveling data indicate a trough of the ground, but the two parameters describing it, $S_{v \max }$ and $i$, are not constant, because ground conditions in urban environment are variable $\left(S_{v \max }\right.$ for example vary by $50 \%$ in nearby points).

\section{Static Soil Structure Interaction (sSSI)}

In the case of Budapest metro (Figure 4b), the distance between tunnel axis and the nearest facades of buildings is nearly constant and subsidence is typically derived from observations on benchmarks in building facades. In certain cases, however, usually when the tunnel axis was crossing areas with buildings on one side and greenfields on the other, benchmarks were established either on building facades, or directly on the ground. The outcome of these studies was that the symmetric pattern of Figure $4 \mathrm{a}$ was violated and in the side of the tunnel proximal to buildings, subsidence was smaller in amplitude and in extension than in the sides of greenfield areas (Figure 5). 


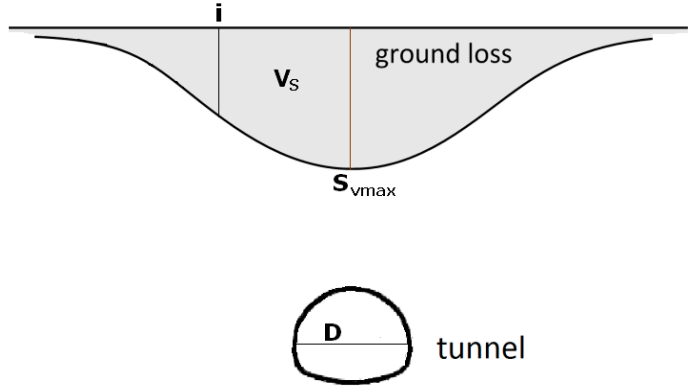

(a)

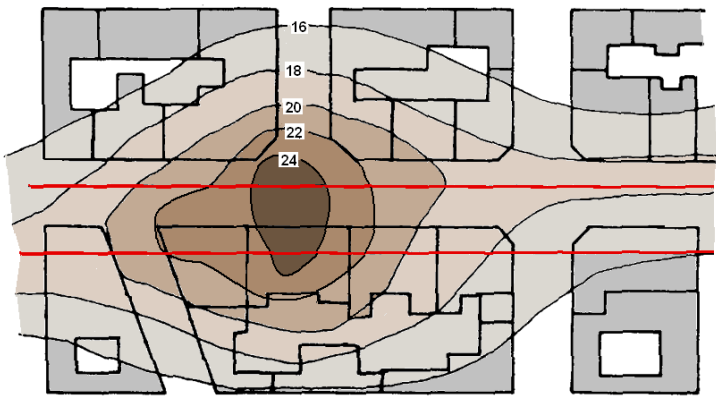

(b)

Figure 4. (a) Idealized pattern of ground loss, which can be approximated by a Gaussian curve, defined by two parameters, $S_{v \max }$ and $i$; (b) typical subsidence trough during the excavation of the Budapest Metro (after [23], modified). Subsidence follows the pattern of Equation (1), but along the trough, the amplitude of subsidence (shown by contours, in $\mathrm{cm}$ ) is variable and 'bowls' of increased subsidence are formed.

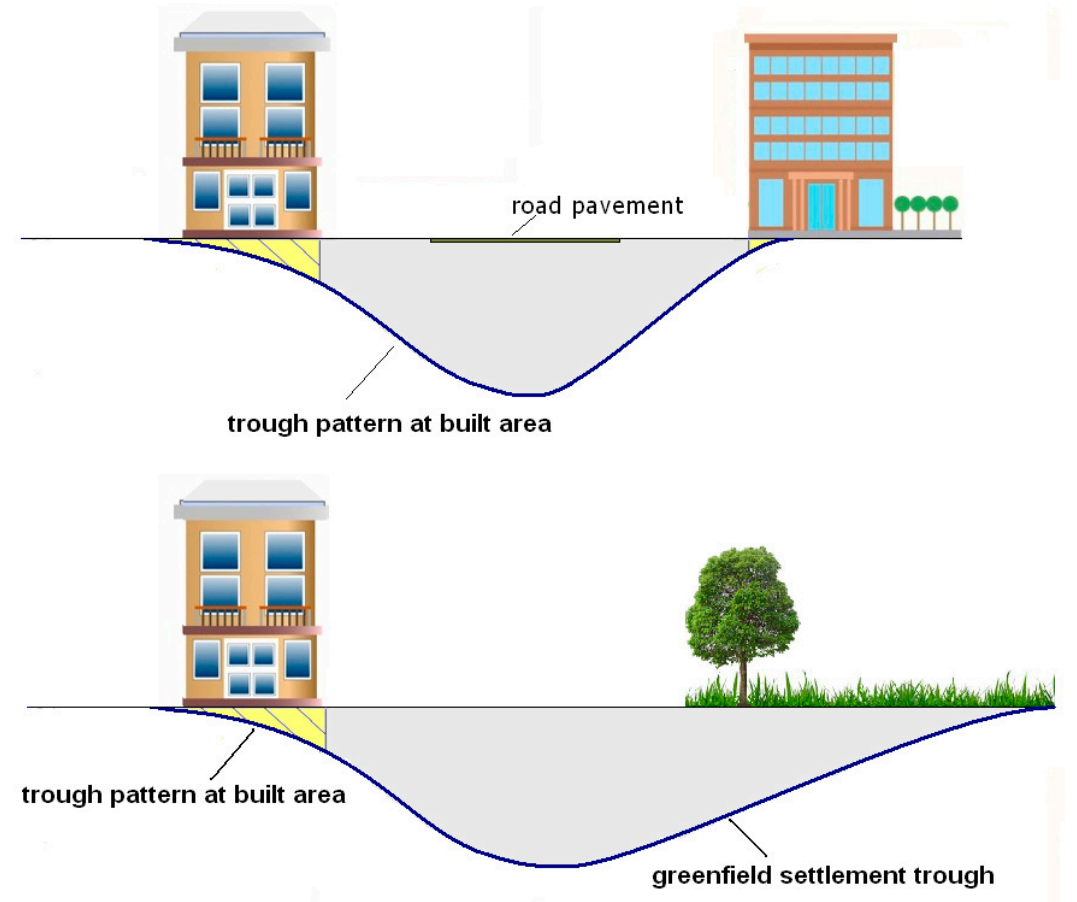

Figure 5. Geodetic observations of ground loss and tilting (benchmarks on building and on ground) indicate symmetric subsidence troughs if buildings exist at both sides of the tunnel (top), but asymmetric if buildings are on one side and a greenfield on the other (bottom).

The explanation proposed for this 'greenfield effect' was that buildings absorbed some of the ground deformation, either because of their stiffness, or because of internal deformation (see [24]). This effect, thereafter static Soil Structure Interaction(sSSI), has been investigated on the grounds of numerical modeling. Several studies on modeling the response of specific buildings to tunneling have been made, and their output is that the interaction between building, ground, and tunnel is particularly difficult to model, requiring various a priori assumptions. For instance, sSSI is regarded as a 2-D problem [5], buildings are simulated as beams [25], or the effects of shear walls are assumed to be minor [26]. Therefore, numerical analyses cannot constrain sSSI well [27]. However, there are also studies including evidence from monitoring records that led to the conclusion that the soil-structure interaction may reduce the predicted tendency of a building to suffer high settlements and damage during tunneling (see for instance [28,29]). 


\section{Evidence from the Athens Metro Line 2}

Certain geodetic monitoring data from the Athens Metro excavation have been recently classified as non-confidential and are available for our research. These data represent the official CSV files of repeated measurements of elevations of benchmarks using geodetic instruments, such as different direct leveling techniques (optical, electronic, and hydraulic leveling) and indirect leveling techniques (using total stations and robotic theodolites). The data cover wider areas above the tunnel sections analyzed, before and long after the excavation of the tunnel and beyond the influence zones of the excavation. There is also available information for the tunnel front advancement, topographic maps with the precise location of the benchmarks, as well as metadata, such as information on the measuring techniques, replacement of benchmarks, etc. These data were evaluated for errors and completeness and were processed. Cases of interaction of double tunnels were excluded. The final product of this preliminary analysis presented in this article is contours of elevation changes of the total subsidence recorded because of a single tunnel line, relative to nearby stable areas.

The output of this analysis (input data) is summarized in Figures 6 and 7 and covers sections of two different lines of the Athens Metro Line 2, between Sepolia and Aghios Antonios station (Kifissos Ave. site) excavated in 2001-2002 at $\approx 40 \mathrm{~m}$ depth in loose Quaternary deposits and between Peristeri and Anthoupoli stations in 2002-2003 (Panagi Tsaldari Ave. site) using an Open Face Shield TBM in a Neogene formation of marls at about 20-25 m depth of the tunnel, respectively. In these graphs, the projection of the tunnel section and nearby buildings are also shown in order to understand the effect of the asymmetry in the distribution of buildings and greenfields around tunnels. In these cases, no structural failure in buildings was observed.

The pattern of ground deformation derived from Figures 6 and 7 is roughly consistent with that predicted by Equation (1), especially since it corresponds to a subsidence trough along the tunnel axis, locally disturbed by bowls of increased local ground deformation (compare points S1 to S4 in Figure 7 with Figure $4 \mathrm{~b}$ ). Still, the data of Figures 6 and 7 covering tunneling through fully built areas and greenfields, show two main differences in comparison to the model of Figure $4 \mathrm{~b}$.

First, in the case of Budapest Metro excavation, the differences in the maximum amplitude of subsidence along the trough $\left(S_{v \max }\right)$ range up to $30 \%(18-24 \mathrm{~mm})$, while the differences in the width of the trough differ by a factor of 2 (Figure $4 \mathrm{~b}$ ). On the contrary, in the cases of the Athens Metro in Figure 6, measured subsidence ranges between 5 and $225 \mathrm{~mm}$, i.e., a difference of $450 \%$, while the width of the trough ranges between 15 and $100 \mathrm{~m}$, a difference of up to $600 \%$. Second, the model of Figure $4 \mathrm{a}$ and Equation (1) are characterized by symmetry in the deformation along the tunnel axis, but not the cases of Figures 6 and 7. Asymmetry is mainly reflected in the increase of the width of the side of the subsidence trough in greenfield areas.

More specifically, geological reports from the construction site at Panagi Tsaldari Ave. suggest no significant variations of the geological and hydrogeological conditions in the study area, nor in the front advancement rate. The excavation was based on OFS (Open Face Shield) TBM excavation through a fair rock mass (GSI values between 25 and 35). This information, along with details on the excavation and its associated risks, was publicized by [30]. A representative cross section of the tunnel is given in Figure 8 (based on [31]). Furthermore, according to the official records, the excavation front progress was at a constant rate of $\approx 5 \mathrm{~m}$ per day and no changes to the support measures or any other modifications to the excavation procedure were reported. 


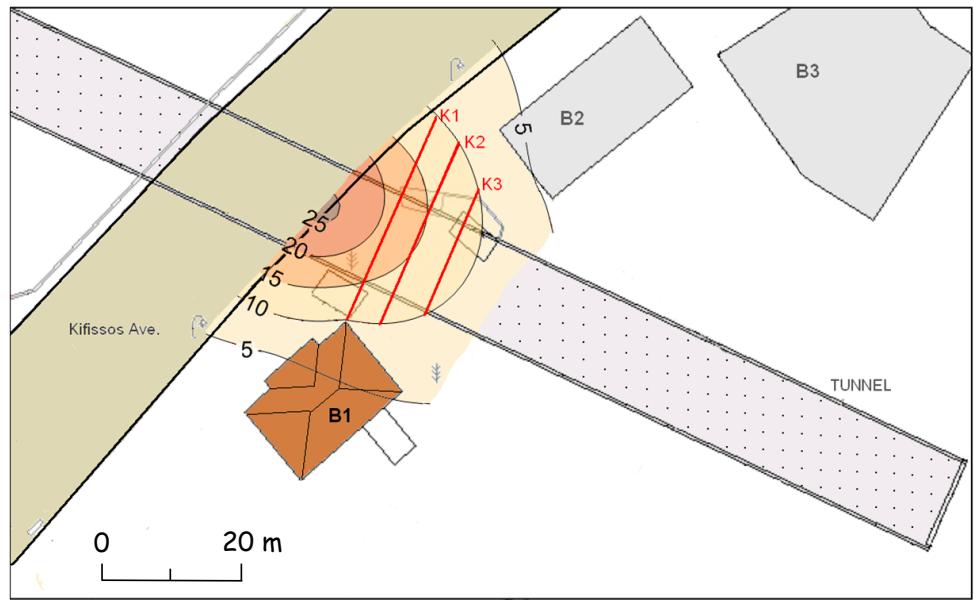

Figure 6. Settlement contours during the excavation of the Athens Metro near Kifissos Ave. Asymmetries in the subsidence trough (ground loss) due to scattering of buildings on the top signify observations on buildings underestimate subsidence due to sSSI. For significant results, only settlements above $10 \mathrm{~mm}$ are examined.

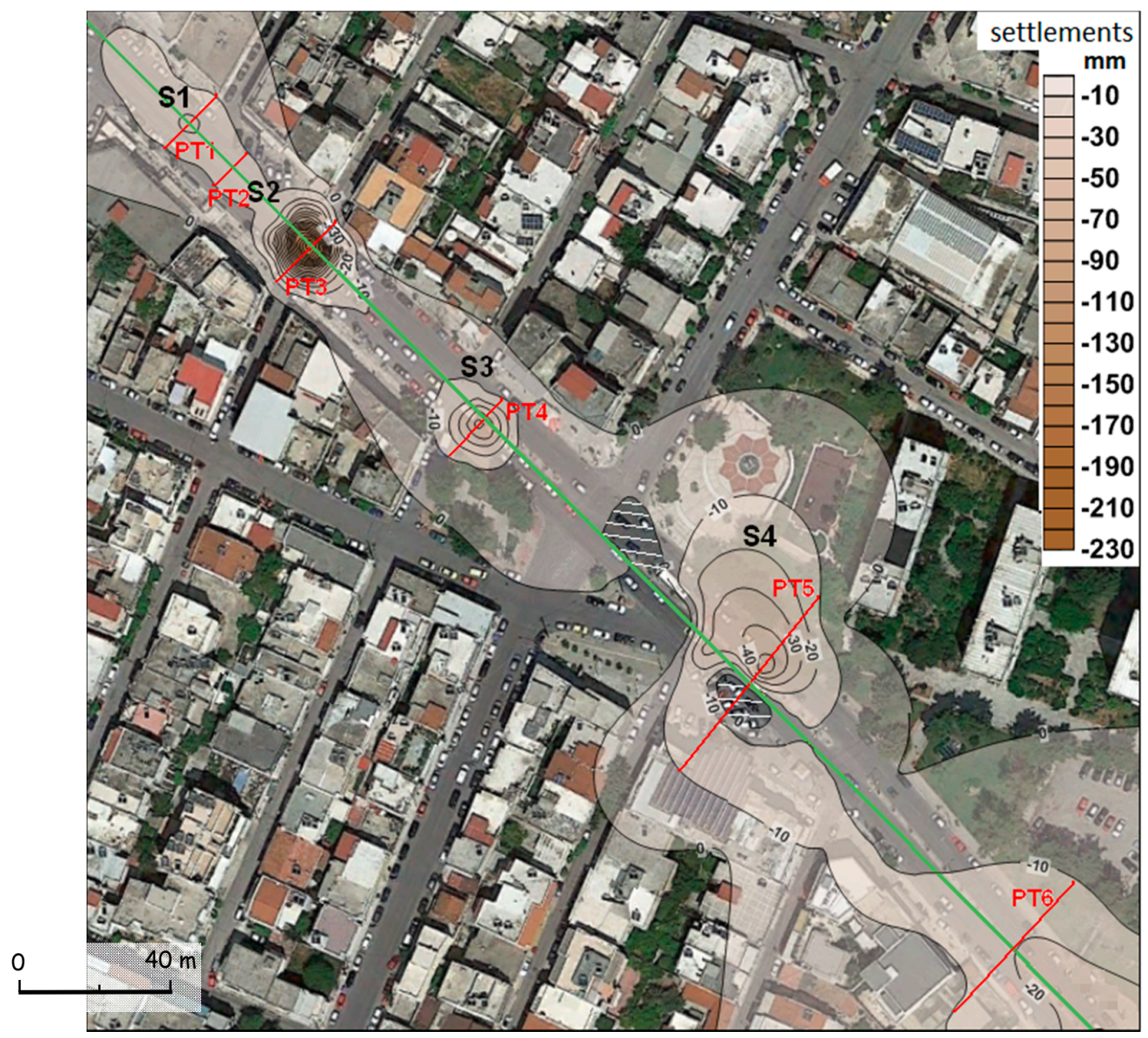

Figure 7. Settlement contours during the excavation of the Athens Metro Line 2 in the Panagi Tsaldari Avenue area superimposed on Google Map background. High subsidence contours are shown by increased color grading. White dashes indicate areas in which monitoring benchnmarks were destroyed and replaced, and observations were discarded because they record only part of the ground deformation. Asymmetries in the subsidence trough (ground loss) related to the distribution of buildings and greenfield areas suggest that observations on buildings underestimate subsidence due to sSSI. For significant results, only settlements above $10 \mathrm{~mm}$ are examined in this article. 


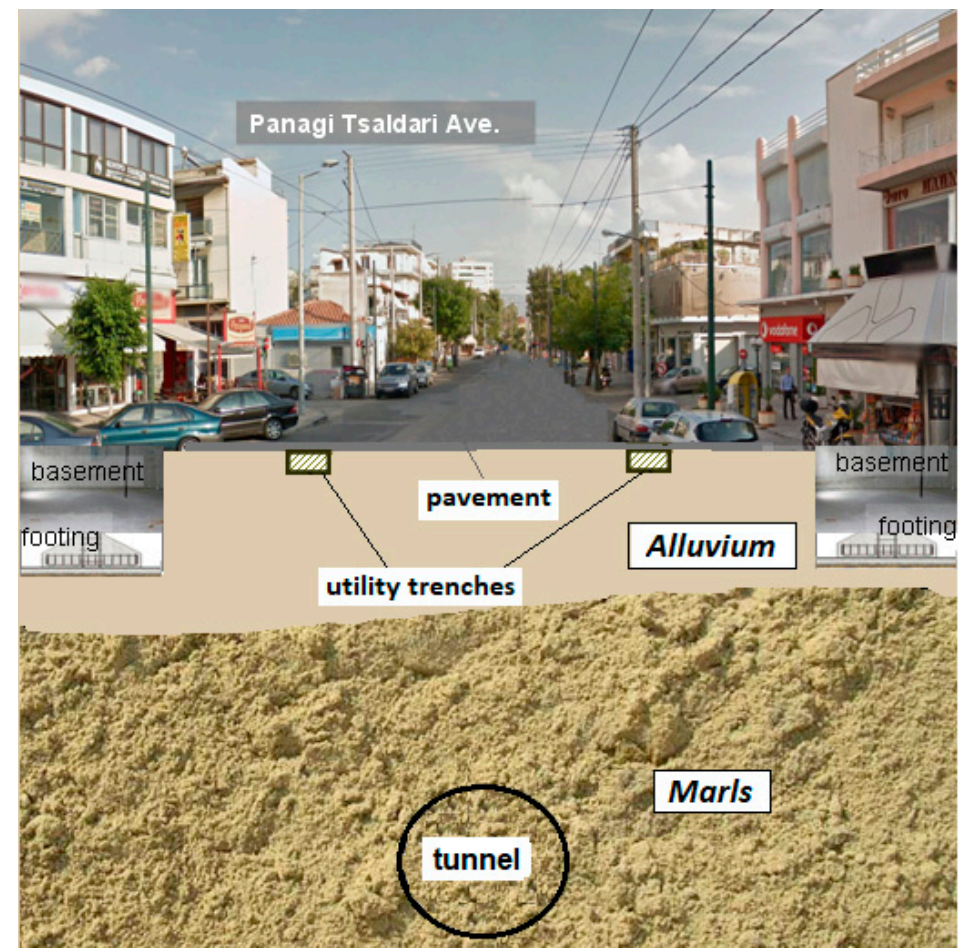

Figure 8. A sketch of the tunnel cross section beneath Panagi Tsaldari Ave (geology taken from [31]). The excavated diameter is $9.5 \mathrm{~m}$ and crown is at $15-20 \mathrm{~m}$ below ground surface.

\section{Discussion}

Figures 6 and 7 indicates that in greenfields the width of recorded subsidence above an advancing tunnel is much higher than in the proximity of various types of buildings, either bulky buildings of large dimensions or even smaller old brick houses. Thus, it is evident that subsidence at built areas normally forms a much narrower trough profile. There are two possible explanations for that; either that ground subsidence is reduced at the ground surface or that because of the interaction between ground and structures local strain is partly concealed. The first alternative can be rejected in most cases, because ground loss is a relatively deep effect, affecting the rock/soil mass above/around the tunnel, until the ground surface, while foundations of buildings are usually shallow and observations are based on benchmarks on the buildings. In a few cases only, for example in Amsterdam or Venice, building foundations include relatively long piles and can make an exception. The second alternative is that SSSI leads to a smoother trough beneath structures related to the higher stiffness of the mixed system of ground and structure. Still, the situation is, however, more complicated. As is analyzed below, ground deformation derived from observations on benchmarks on bulky structures is recorded with some hysteresis, and only after it exceeds a certain threshold. These obscure the pattern of "true" ground deformation.

\subsection{Amount and Timing of Recorded Ground Deformation}

Bulky buildings modify the pattern and amplitude of ground deformation either because of their stiffness or of internal strain. For this reason, in Figure 9 the original ground surface (1) would take the form of curve (3) in greenfield, but monitoring stations on the buildings testify to a settlement trough defined by curve (2). The trough pattern is further affected by the fact that monitoring targets are placed mostly on structures of interest and not across the whole tunnel influence zone; so, the available data are confined to specific areas and troughs across the tunnel axis are designed with interpolation techniques using limited data. 


\subsection{Uncertainties in Observations}

Observations of subsidence derive either from various types of leveling (leading to direct or indirect measurement of vertical movements), and/or indirectly from tilting, in combination with models such as that of Equation (1). Furthermore, all measurements are characterized by an uncertainty (error, noise) typically between one and a few millimeters.

This uncertainty is convenient to be regarded in terms of SNR (signal-to-noise ratio), i.e., of the ratio between mean amplitude of displacement to the mean amplitude of uncertainty in measurements. For example, leveling measurements close to the ground surface are influenced by atmospheric effects (low SNR) and their quality is much lower than in higher levels (higher SNR). Similarly, the accuracy of estimation of tilting increases with the height of studied structure, and is low for a typical fence but high for a tower (high SNR). Similarly, at the edges or at the early stages of formation of a subsidence trough (for instance at the edges of the troughs of Figure 5), the amplitude of dislocation and its SNR are small and do not describe precisely, even they may not detect the "true" dimensions of the impact. Hence the extent of the subsidence trough tends to be underestimated. The implications of this situation are summarized in Table 1.

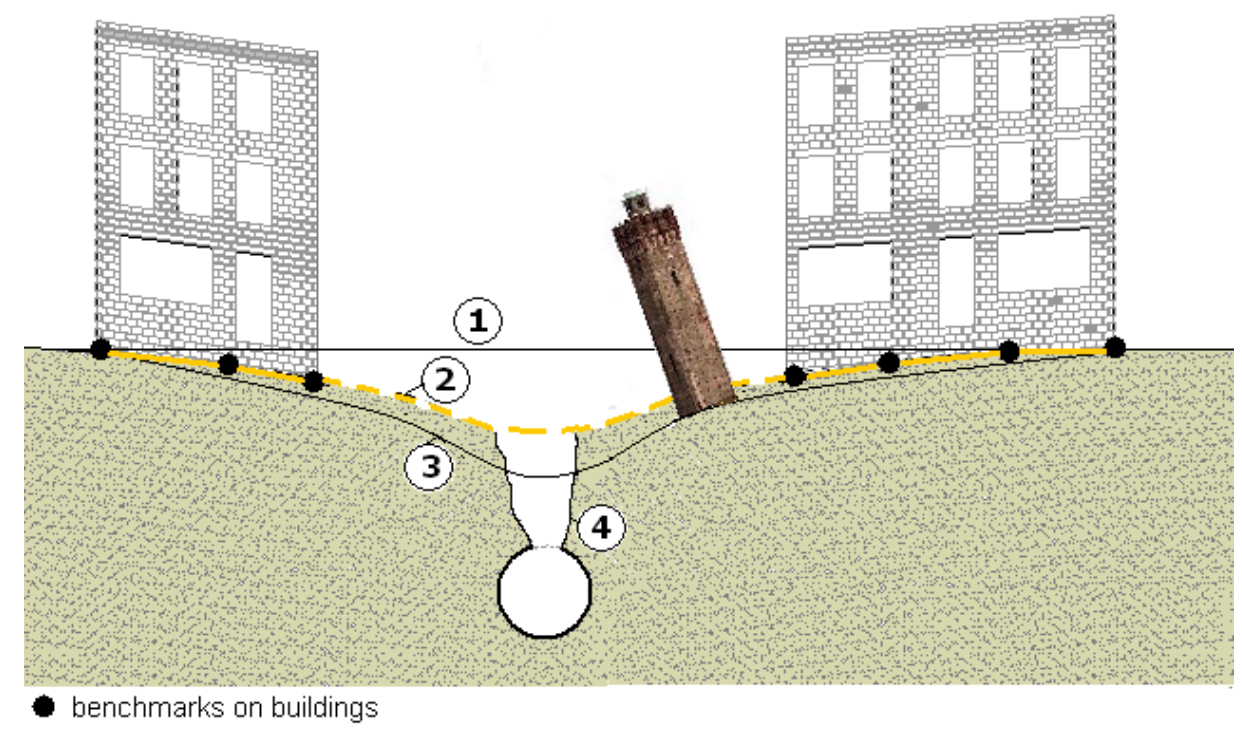

Figure 9. A conceptual model to explain ground loss: (1) original ground surface; (2) ground surface derived from subsidence of benchmarks (marked by solid circles) mainly on buildings. Dashed line indicates trough designed by interpolation (due to limitation in recording data); (3) predicted ground surface at greenfield, following the Gaussian curve introduced by Peck [1]; (4) formation of sinkhole (daylight failure).

\subsection{Implications for Modeling of the Subsidence Curve and Unexpected Failures}

The problem with sSSI, however, is not limited to the amount of subsidence but extends also to its timing [32,33]. Small amounts of subsidence may be concealed because of the combined effect of SNR and SSI and evidence of ground subsidence and tilting may appear only after the true ground deformation exceeds a certain threshold which depends on the ground characteristics and the inertial properties of structures. For this reason, early (and critical) phases of deformation may remain unnoticed. This may have destructive implications: monitoring for ground loss based on benchmarks on buildings may not identify early phases of deformation of buildings or of the ground, which may in fact fail without previous notice. 
Table 1. Signal-to-noise ratio (SNR) for the recorded subsidence at various cases of the surface above tunneling.

\begin{tabular}{ccc}
\hline & $\begin{array}{c}\text { Width of Half Part } \\
\text { of Subsidence Trough }\end{array}$ & $\begin{array}{c}\text { SNR } \\
\text { (Signal to Noise Ratio) }\end{array}$ \\
\hline Free field zone & $\begin{array}{c}\text { Precisely estimated. } \\
\text { (but underestimated if subsidence } \\
\text { amplitude is small). }\end{array}$ & $\begin{array}{c}\text { Depending on subsidence amplitude. } \\
\text { (SNR proportional to subsidence } \\
\text { amplitude). } \\
\text { Isolated tower }\end{array}$ \\
Bulky building & $\begin{array}{c}\text { Precisely estimated. } \\
\text { Underestimated subsidence. } \\
\text { Strains partly accommodated by }\end{array}$ & Small. \\
& building stiffness. & \\
\hline
\end{tabular}

This is perhaps the explanation for some 'unexplained' sinkholes. For example, during the excavation of the Athens Metro line 1, a $10 \mathrm{~m}$ wide and $15 \mathrm{~m}$ deep (until the tunnel roof) sinkhole occurred at the excavation site of Doukissis Plakentias Ave. in January 2003 (see Figure 3), but for this event no formal technical information is available. A possible scenario for this last sinkhole is that it occurred in an area with few structures close to the tunnel axis and hence with very few monitoring benchmarks. The tunnel advance was stopped for the New Year's Day holidays permitting accumulation of deformation due to relaxation of the ground. When the excavation resumed in early January, the (unnoticed) deformation of the soil above the tunnel exceeded a critical threshold, indicating widening of the plastic zone around the tunnel, and possibly in combination with a local effect (possibly an abandoned buried well, among those often met at this area) and/or because of additional deformation induced by the resumed tunnel excavation (cf. [2]), produced the sinkhole.

\subsection{Pattern of Ground Subsidence}

The model of Figure 3a describes a 2-D effect, but, because of the gradual advancement of the tunnel excavation front, the ground deformation becomes a 3-D effect $[11,13,17]$. Still, monitoring points, especially on the facades of buildings, usually parallel to the tunnel axes (see Figure 1a) can only record tilting down-to-the tunnel axis, i.e., a 2-D effect. This is because the component of ground tilting parallel to the tunnel axis (and to the facades of the buildings) is counteracted and masked by the interaction of adjacent buildings (Figure 1a). This limitation does not cover slender structures with small, isolated foundations, such as those of Figures $1 \mathrm{c}$ and $2 \mathrm{f}$ (see [17]).

In order to further investigate the pattern of the ground subsidence perpendicular to the tunnel at built areas, first we explored the asymmetry of the subsidence troughs (Figure 5) and considered sections along the tunnel axis for Panagi Tsaldari Ave. and Kifissos Ave. with symmetric and asymmetric troughs normal to the axis (Figures 6 and 7). For all nine sections we measured the distance left and right of the tunnel axis from the closest building $\left(d_{l}\right.$ and $d_{r}$, respectively; indicating left and right of the tunnel axis) and the corresponding width of the subsidence trough up to the contour of $10 \mathrm{~mm}, \ell_{l}$ and $\ell_{r}$, respectively. We also divided these sections in three classes, depending on the background of monitoring points: 'building-to-building' (B-B) for both $d_{l}$ and $d_{r}<2.5 \mathrm{D}$ (D: tunnel diameter, i.e., the mean width of the tunnel influence zone; [1]), 'greenfield-to-building' (G-B) for $d_{l}$ or $d_{r}>2.5 \mathrm{D}$ (D: tunnel diameter) and 'greenfield-to-greenfield' (G-G), if both $d_{l}$ and $d_{r}>2.5 \mathrm{D}$ (i.e., the width of the tunnel influence zone).

To compare the sections, we calculated the environs asymmetry ratio $E$ (i.e., asymmetry in building distance) and the skewness of the trough ratio $S$ as follows:

$$
\begin{aligned}
& E=d_{l} / d_{r} \\
& S=\ell_{l} / \ell_{r}
\end{aligned}
$$

selecting $l, r$ in each section so that $d_{l}>d_{r}$ and $\ell_{l}>\ell_{r}$. 
All these data are summarized in Table 2. In Figure 10, we plotted the ratio of environs asymmetry $E$ as a function of the skewness of the subsidence trough $S$. A striking contrast between observations of tunnel influence zone in uniform environment (B-B, G-G) and non-uniform environment (G-B) is observed. This contrast indeed indicates a bias in observations of tunnel influence zone because of sSSI, which is not evident in observations in uniform environmental conditions (B-B).

Table 2. Nine representative sections drawn along the metro tunnel axis at Panagi Tsaldari Ave., marked as PT1 to PT6, and Kifissos Ave., marked as K1 to K3 (shown in Figure 4). Distance of tunnel axis up to the closest building at left and right and the corresponding trough width are measured. Environs asymmetry ratio $E$ and trough skewness ratio $S$ are calculated using Equations (2) and (3). Section type (B-B, G-B, or G-G) is marked.

\begin{tabular}{|c|c|c|c|c|c|c|c|c|}
\hline Section & $\begin{array}{l}\text { Type of } \\
\text { Section }\end{array}$ & $\begin{array}{l}S_{v \max } \\
(\mathrm{mm})\end{array}$ & $\begin{array}{c}\text { Distance } \\
\text { to } \\
\text { Building } \\
\text { at Left } \\
\text { Side (m) } \\
d_{l}\end{array}$ & $\begin{array}{c}\text { Distance } \\
\text { to } \\
\text { Building } \\
\text { at Right } \\
\text { Side (m) } \\
d_{r}\end{array}$ & $\begin{array}{c}\text { Trough } \\
\text { Width at } \\
\text { Left Side } \\
\text { (m) } \\
\ell_{l}\end{array}$ & $\begin{array}{c}\text { Trough } \\
\text { Width at } \\
\text { Right } \\
\text { Side }(\mathrm{m}) \\
\ell_{r}\end{array}$ & $\begin{array}{c}\text { Environs } \\
\text { Asymmetry } \\
\text { Ratio } \\
E\end{array}$ & $\begin{array}{c}\text { Trough } \\
\text { Skewness } \\
\text { Ratio } \\
\text { S }\end{array}$ \\
\hline PT1 & B-B & 24 & 14 & 14 & 13 & 9 & 1 & 0.69 \\
\hline PT2 & B-B & 11 & 14 & 14 & 6 & 7 & 1 & 0.86 \\
\hline PT3 & B-B & 220 & 6 & 14 & 8 & 10 & 0.57 & 0.8 \\
\hline PT4 & G-B & 58 & 14 & 25 & 7 & 14 & 1.78 & 2 \\
\hline PT5 & $\mathrm{G}-\mathrm{G}$ & 78 & 25 & 25 & 26 & 28 & 1 & 0.93 \\
\hline PT6 & G-B & 20 & 25 & 14 & 23 & 15 & 1.78 & 1.53 \\
\hline K1 & G-B & 18 & 25 & 8 & 13 & 8 & 3.12 & 1.62 \\
\hline $\mathrm{K} 2$ & G-B & 15 & 25 & 10 & 12 & 7 & 2.5 & 1.71 \\
\hline K3 & B-B & 12 & 15 & 12 & 8 & 5 & 0.8 & 0.62 \\
\hline
\end{tabular}

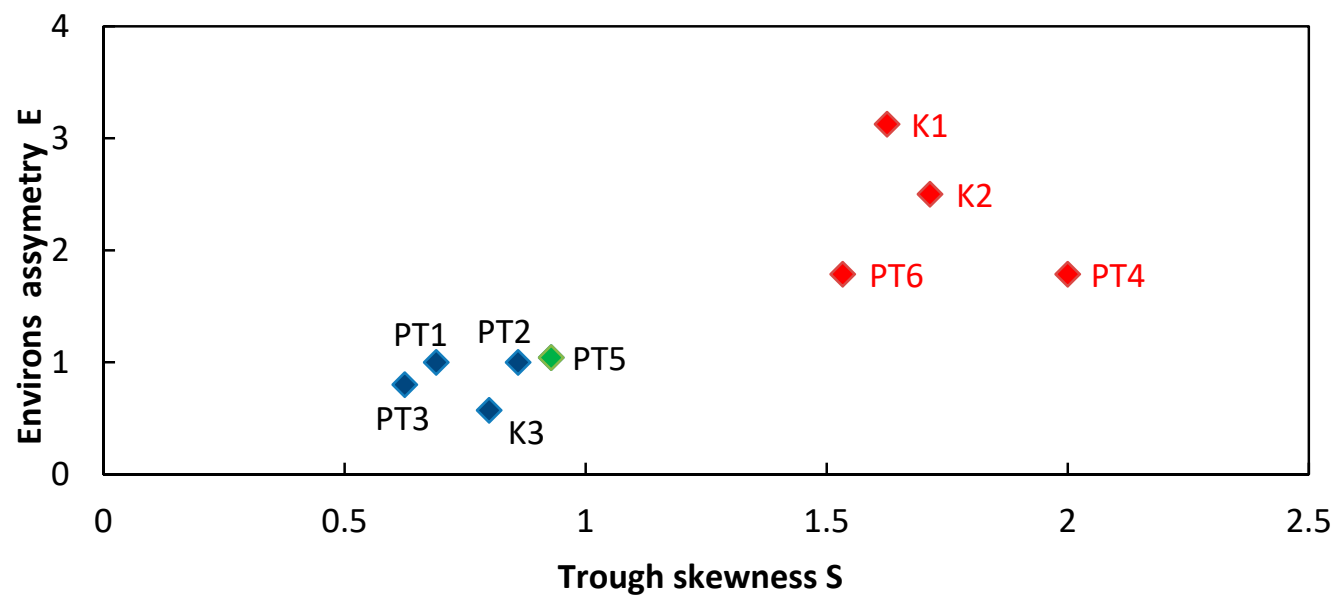

Figure 10. Environs asymmetry ratio $E$ (distance to buildings) as a function of the subsidence trough skewness ratio $S$. Data as in Table 2. Skewness ratio $S$ is minimum in uniform greenfield areas (PT5, in green) and maximum in sections with buildings at one side of the tunnel axis (Building-Greenfield, i.e., PT4, PT6, K1, K2 shown in red).

\section{Conclusions}

Analysis of monitoring data from the Athens Metro lines permit to investigate the problem of sSSI during urban tunneling. Observations on benchmarks in greenfields and on isolated towers are usually free of the sSSI impacts and offer an unbiased estimation of the "true" ground loss. On the contrary, observations of ground settlement of urban tunnels are usually based on benchmarks on buildings and tend to present a biased pattern of the subsidence curve: underestimation of subsidence, masking of its 3-D character, and an apparent skewness in subsidence curves because much of the local ground surface deformation is concealed due to sSSI. Hence, it seems likely that failures such as 
damage in buildings, and to sinkhole development are related to underestimation of the "true" ground loss. This result is important for the planning of future projects, for the interpretation of monitoring data during tunnel excavation, as well as for the interpretation of certain cases of failure related to tunnel excavation for which no information exists.

Author Contributions: Conceptualization, V.K.; methodology, V.K. and S.C.S.; formal analysis, V.K. and S.C.S.; resources, V.K. and S.C.S.; data curation, V.K. and S.C.S.; writing-original draft, V.K. and S.C.S.; writing-review and editing, V.K.; visualization, V.K. All authors have read and agreed to the published version of the manuscript.

Funding: This research received no external funding.

Acknowledgments: Attiko Metro SA and M. Novak in particular are thanked for valuable information and monitoring data. This paper benefited from comments of two anonymous reviewers. These results do not mean that Attiko Metro endorses our views or that it recognizes any legal impacts from this publication.

Conflicts of Interest: The authors declare no conflict of interest.

\section{References}

1. Peck, R.B. Advantages and limitations of the observational method in applied soil mechanics. Geotechnique 1969, 19, 171-187. [CrossRef]

2. Kontogianni, V.; Psimoulis, P.; Pytharouli, S.; Stiros, S. Geodetic monitoring of underground excavations: 70 years after Terzaghi's innovative techniques at the Chicago subway tunnels. In Proceedings of the 5th International Symposium of the International Society for Soil Mechanics and Geotechnical Engineering, Amsterdam, The Netherlands, 15-17 June 2005; pp. 31-36.

3. Burland, J.B.; Standing, J.R.; Jardine, F.M. Building Responses to Tunneling-Case studies from Construction of the Jubilee Line Extension; Thomas Telford: London, UK, 2001; Volume 1.

4. Ritter, S.; Giardina, G.; DeJong, M.J.; Mair, J. Influence of building characteristics on tunnelling-induced ground movements. Géotechnique 2017, 67, 926-937. [CrossRef]

5. Giardina, G.; DeJong, M.J.; Mair, R.J. Interaction between surface structures and tunnelling in sand: Centrifuge and computational modelling. Tunn. Undergr. Space Technol. 2015, 50, 465-478. [CrossRef]

6. Harris, D.I. Building Response to Tunnelling - The Clock Tower and The Palace of Westminster; Thomas Telford: London, UK, 2002; Chapter 28.

7. Kavvadas, M. Monitoring ground deformation in tunnelling: Current practice in transportation tunnels. Eng. Geol. 2005, 79, 93-113. [CrossRef]

8. Finno, R.; Bryson, L. Response of building adjacent to stiff excavation support system in soft clay. J. Perform. Constr. Facil. 2002, 16, 10-20. [CrossRef]

9. Kaalberg, F.J. Advanced Modeling to Support Innovative Developments in Tunneling for Amsterdam North/South Line. In Finite Elements in Civil Engineering Applications, Proceedings of the Third DIANA World Conference on Finite Elements in Civil Engineering Tokyo, 9-11 October 2002; A.A. Balkema Publisher: Tokyo, Japan, 2002.

10. Finno, R.; Voss, F.; Rossow, E.; Blackburn, T.J. Evaluating Damage Potential in Buildings Affected by Excavations. J. Geotech. Geoenviron. Eng. 2005, 131, 1199-1210. [CrossRef]

11. Finno, R.; Blackburn, J.T.; Roboski, J. Three-dimensional effects for supported excavations in clay. J. Geotech. Geoenviron. Eng. 2007, 133, 30-36. [CrossRef]

12. Son, M.; Cording, E. Responses of buildings with different structural types to excavation-induced ground settlements. J. Geotech. Geoenviron. Eng. 2011, 137, 323-333. [CrossRef]

13. Namazi, E.; Mohamad, H. Assessment of building damage induced by three-dimensional ground movements. J. Geotech. Geoenviron. Eng. 2013, 139, 608-618. [CrossRef]

14. Farrell, R.; Mair, R.; Sciotti, A.; Pigorini, A. Building response to tunnelling. Soils Found. 2014, 54, $269-279$. [CrossRef]

15. Bjureland, W.; Spross, J.; Johansson, F.; Prästings, A.; Larsson, S. Reliability aspects of rock tunnel design with the observational method. Int. J. Rock Mech. Min. Sci. 2017, 98, 102-110. [CrossRef]

16. Van Hasselt, D.R.S.; Hentschel, V.; Hutteman, M. Amsterdam's north/south metroline. Tunn. Undergr. Space Technol. 1999, 14, 191-210. [CrossRef] 
17. Papastamos, G.; Stiros, S.; Saltogianni, V.; Kontogianni, V. 3-D strong tilting observed in tall, isolated brick chimneys during the excavation of the Athens metro. Appl. Geomat. 2015, 7, 115. [CrossRef]

18. Science Alert. This Gigantic Sinkhole in Ottawa Just Took Out a 4-Lane Road. 2016. Available online: www.sciencealert.com/gigantic-sinkhole-in-canada-s-capital-ottawa-may-have-been-caused-byquick-clay (accessed on 30 July 2020).

19. Kathimerini Newspaper. 2003. Available online: www.kathimerini.gr/139341/article/epikairothta/ellada/htrypa-sto-metro-ek8eteiergolavoys-kai-mhxanikoys (accessed on 30 July 2020). (In Greek).

20. Kontogianni, V.; Pytharouli, S.; Stiros, S. Ground subsidence, quaternary faults and vulnerability of utilities and transportation networks in Thessaly, Greece. Environ. Geol. 2007, 52, 1085-1095. [CrossRef]

21. Mair, R.J.; Taylor, R.N.; Burland, J.B. Prediction of Ground Movements and Assessment of Risk of Building Damage Due to Bored Tunneling. In Proceedings of the International Symposium on Geotechnical Aspects of Underground Construction in Soft Ground, London, UK, 15-17 April 1996; pp. 713-718.

22. Maravas, A.; Mylonakis, G.; Karabalis, D. Dynamic Soil-Structure Interaction for SDOF Structures on Footings and Piles. In Proceedings of the Geotechnical Earthquake Engineering and Soil Dynamics IVGSP181, Sacramento, CA, USA, 18-22 May 2008. [CrossRef]

23. Szechy, K. The Art of Tunneling; Hungarian Academy of Sciences: Budapest, Hungary, 1973.

24. Franzius, J.N.; Potts, D.M.; Burland, J.B. The response of surface structures to tunnel construction. Proc. Inst. Civ. Eng. Geotech. Eng. 2006, 159, 3-17. [CrossRef]

25. Pickhaver, J.A.; Burd, H.J.; Houlsby, G.T. An equivalent beam method to model masonry buildings in 3D finite element analysis. Comput. Struct. 2010, 88, 1049-1063. [CrossRef]

26. Goh, K.H.; Mair, R.J. Response of framed buildings to excavation-induced movements. Soils Found. 2014, 54, 250-268. [CrossRef]

27. Franza, A.; Marshall, A.; Haji, T.; Abdelatif, A.O.; Carbonari, S.; Morici, M. A simplified elastic analysis of tunnel-piled structure interaction. Tunn. Undergr. Space Technol. 2017, 61, 104-121. [CrossRef]

28. Burd, H.J.; Houlsby, G.T.; Augarde, C.E.; Liu, G. Modelling tunnelling-induced settlements of masonry buildings. Proc. Inst. Civ. Eng. Geotech. Eng. 2000, 143, 17-29. [CrossRef]

29. Bilotta, E.; Paolillo, A.; Russo, G.; Aversa, S. Displacements induced by tunnelling under a historical building. Tunn. Undergr. Space Technol. 2017, 61, 221-232. [CrossRef]

30. Marinos, P.; Marinos, V.; Stoumpos, G.; Novak, M.; Korkaris, K.; Benissi, M. Behaviour of the "Athenian schist" in excavation by an open face shield boring machine extension line to peristeri of the metropolitan railway of Athens. Bull. Geol. Soc. Greece 2004, 36, 1790-1795. [CrossRef]

31. Kynigalaki, M.; Nikolaou, N.; Karfakis, J.; Koutsouveli, A.; Poyiadji, E.; Pyrgiotis, L.; Konstantopoulou, G.; Bellas, M.; Apostolidis, E.; Loupasakis, K.; et al. Digital engineering geological map of the Athens Prefecture area and related Database Management System. Bull. Geol. Soc. Greece 2010, 43, 1619-1626. [CrossRef]

32. Kontogianni, V.; Psimoulis, P.; Stiros, S. What is the contribution of time-dependent deformation in tunnel convergence. Eng. Geol. 2006, 82, 264-267. [CrossRef]

33. Sulem, J.; Panet, M.; Guenot, A. Closure analysis in deep tunnels. Int. J. Rock Mech. Min. Sci. Geomech. Abstr. 1987, 24, 145-154. [CrossRef]

(C) 2020 by the authors. Licensee MDPI, Basel, Switzerland. This article is an open access article distributed under the terms and conditions of the Creative Commons Attribution (CC BY) license (http://creativecommons.org/licenses/by/4.0/). 